\title{
A LONG PROCESS TOWARDS AGRICULTURE IN THE MIDDLE YELLOW RIVER VALLEY, CHINA: EVIDENCE FROM MACRO- AND MICRO-BOTANICAL REMAINS
}

\author{
Li Liu
}

\author{
Department of East Asian Languages and Cultures, Stanford University, liliu@stanford.edu \\ Keywords: Origins of agriculture; starch analysis; grinding stones; Upper Paleolithic; early Neolithic; archaeobotany
}

\begin{abstract}
Macro- and micro-botanical remains dating from the Upper Paleolithic through early Neolithic periods in North China have provided significant information for reconstructing the changing subsistence patterns as human groups evolved from mobile hunting-gathering societies to sedentary farming communities. Starch analysis on grinding stones, in particular, has revealed much new data that supplement the inventory of carbonized remains recovered by flotation methods. This paper reviews some recent research projects which have documented a long tradition of processing various plants with grinding stones in the Middle Yellow River valley, including tubers, beans, nuts, and cereals. Exploitation of wild millet can be traced back to 23,000-19,500 cal. BP, more than 10,000 years before its domestication. Several species of tuber, acorn, and wild grasses made up significant proportions of staple food during the early Neolithic, when millet domestication was already underway. These new data help us to better understand the extended transitional process to agriculture in the Middle Yellow River region. Archaeobotany is in an early stage of development in China; it is important to employ an interdisciplinary approach for a more complete documentation of plant use in the past and a better understanding of subsistence practices then.
\end{abstract}

\section{INTRODUCTION}

Recent archaeological findings suggest that the transition from mobile hunting-gathering societies to sedentary farming communities in China was a very long process, and different regions experienced diverse trajectories to a Neolithic way of life that was often characterized by domestication of plants and animals. In regard to plant domestication, archaeobotanical studies based on macroremains have indicated that North China was the regional center where foxtail millet (Setaria italica spp. italica) and broomcorn millet (Panicum miliaceum) were first domesticated as major dry-land crops (Zhao 2011; 2014). Within this geographical context, the Yellow River valley is one of the areas in which a millet-based agriculture system first emerged.

The employment of flotation methods in recent decades in China has revolutionized our understanding of plant use in prehistory. However, many sites excavated before the 1990s did not benefit from use of this method. Moreover, macro-botanical remains recovered by flotation may manifest only a part of the plant inventories in ancient diets. It is therefore important to employ a multidisciplinary approach to recover more complete archaeobotanical information from archaeological contexts, in order to reconstruct a fuller picture of past subsistence practices.

Micro-botanical study and usewear analysis of artifacts have shown great potentials for obtaining information on human exploitation of plants (e.g., Dubreuil 2004; Fullagar and Jones 2004; Fullagar et al. 2008). These methods have also been employed to study artifacts from the late Pleistocene (Guan et al. 2014; Liu et al. 2011; Liu et al. 2013a), the early Holocene (Liu et al. 2010b; Yang et al. 2012a; Yang et al. 2014) and the early Neolithic period (Liu et al. 2010a; Zhang, Y. et al. 2011b) in the Yellow River region. Starch analysis of food processing tools has revealed fine-resolution data on plant use. This method is particularly useful for studying the sites excavated prior to the employment of flotation methods, and therefore can supplement the information derived from macro-botanical analysis.

The term Upper Paleolithic in China generally refers to the period of the late Pleistocene when the material remains are characterized by chipped stone tools with an absence of plant/animal domestication and sedentism. Although China holds the earliest record of pottery making in the world, dating to 20,000 years ago (Wu et al. 2012), this innovation did not seem to have changed the mobile hunting-gathering subsistence strategies. Therefore, I do not regard the presence of pottery as an indicator of the beginning of the Neolithic. The Neolithic in this paper is defined as the presence of a series of technological and social developments, including domestication of plants and animals, the practice of sedentism, and the common use of pottery and ground stone tools. Based on the archaeological data currently available, these developments appeared as a material assemblage around 9000 
years ago. The period from the onset of the Holocene to the beginning of the Neolithic (ca. 11,700-9000 cal. BP) is regarded as a transitional phase in this study.

This paper reviews the new data generated from starch analysis of grinding stones found at two Upper Paleolithic sites and at eight Neolithic sites in the Middle Yellow River region (including Henan, southern Shanxi and southern Hebei provinces), most of which were excavated without flotation techniques. The results demonstrate a variety of plants exploited by humans for a very long time period, from the Upper Paleolithic through the early Neolithic period (23,000-7000 cal. BP). These studies, together with macro-botanical research, can help us reconstruct for this part of North China, some possible trajectories to food production that may be compared with analogous developmental paths in other regions of the world. Locations of the sites discussed in the paper are shown in Figure 1 .

\section{MACRO-BOTANICAL REMAINS}

Only a small number of sites in the Yellow River Valley dating from the Upper Paleolithic to the Early Neolithic have been subjected to the flotation method and charred seeds have been recovered, suggesting a gradual change from wild grass foraging to cereal-based farming. Wild Setaria and Echinochloa spp. were present at Shizitan Locality 9 in Shanxi by13,800-11,600 cal. BP (Bestel et al. 2014). The earliest evidence for the cultivation of Setaria sp., on the basis of morphological change, has been discovered from Donghulin in Beijing (ca. 10,000 cal BP) (Zhao 2014). Millet domestication became widespread by $8000-7000$ cal BP along the Yellow River region, stretching across a range from Shandong and Henan to Gansu (Crawford et al. 2013; Lee et al. 2007; Liu 2006). Although rice has also been found at several sites north of the Huai River, such as Jiahu in Henan (Liu et al. 2007; Zhao and Zhang 2009) and Yuezhuang in Shandong (Crawford et al. 2013), foxtail and broomcorn millets appear to have been the predominant crops cultivated in this region. In the Middle Yellow River valley, in particular, the macro-botanical remains from ten sites, dating to the Upper Paleolithic and Early Neolithic, show that cereals and nuts are much more frequently represented than tubers and roots in the plant assemblages (Table 1). This inventory, however, is not likely to be a complete list of the plants exploited by ancient peoples, and other methods need to be used to recover more plant remains.

\section{FOOD GRINDING IN PALEOLITHIC AND NEOLITHIC TIMES}

Food grinding technology was developed as a part of modern human behavior, and can be traced back to as early as 200,000 years ago in Africa (Fullagar 2006; Van Peer et al. 2003). This technology became much more widespread in the world by ca. 30,000-23,000 years ago, exemplified by the grinding implements found in the Near East, Europe, and Australia (Fullagar and Field 1997; Piperno et al. 2004; Revedin et al. 2010). These tools were used primarily for processing plant foods for human consumption, as indicated by residue and usewear analyses, although use on non-plant foods and non-food materials may have also been parts of their function (e.g., Adams 2010; Dubreuil 2004; Ebeling and Rowan 2004; Wright 1994).

In north China, intensive food grinding can be traced back to ca. $25,000-11,600$ cal BP, indicated by grinding stones found at Shizitan (Shizitan Archaeology Team 2010; 2013) and Xiachun (Lu 1999; Wang et al. 1978), both in Shanxi, and Longwangchan in Shaanxi (Zhang et al. 2011a). This technology continued to be a dominant tradition of food preparation during the early Holocene (ca. 11,700-9000 cal BP), when millet cultivation may have begun, exemplified by Donghulin in Beijing (Archaeology Department et al. 2006) and Nanzhuangtou in Hebei (Li et al. 2010). During the early Neolithic period (ca. 9000-7000 cal. BP), grinding stones were commonly used by people of the Peiligang and Cishan cultures in the Middle Yellow River valley. However, use of this technology diminished during the Yangshao culture of the middle Neolithic period, when population densities increased significantly and millet agriculture became established (ca. 7000-5000 cal. BP). The changing distributional patterns of this tool type thus suggest that grinding stones are likely to have been associated with an intensive foraging economy before agriculture became a dominant subsistence strategy in this region. Understanding what plants were ground on these tools, therefore, will shed light on the subsistence practice then.

Usewear analysis on grinding stones which were examined for residue remains in this study suggests that these tools were all used, although not exclusively, for processing plants. Starch residues uncovered from the same tools indicate that they were used for processing primarily wild foods. Grass husk phytoliths have rarely been recovered, indicating that these tools are unlikely to have been used to dehusk cereals. This paper focuses on results of starch analysis.

It is notable that the percentages of starch grains of certain plants recovered from stone tools cannot be directly used to determine the proportion of plants used in the subsistence system of the past, since some plants may have been consumed without being ground. However, the starch data help us to understand, in a broad view, the components of those starchy foods, as processed with the tools that contributed to human diets. If certain patterns of starch components are repeatedly found in multiple cases and at multiple sites, they are probably meaningful for the reconstruction of the human subsistence patterns. In addition, combining data generated from macro-botanical analysis with residue remains we can provide a more holistic picture of plant exploitation in the region. 


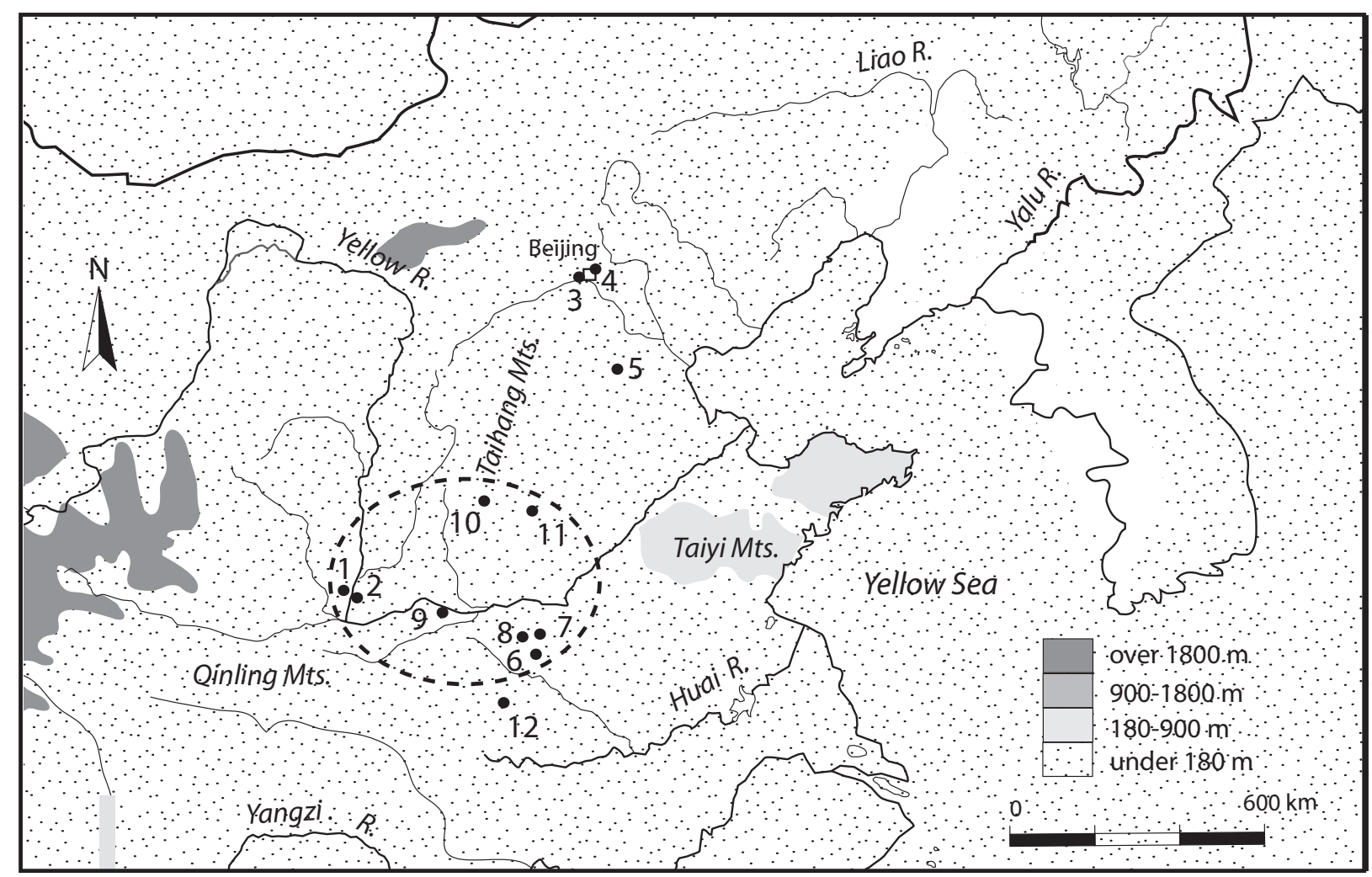

Figure 1. Location of major sites discussed in the text (dashed circle: the study area). 1: Longwangchan; 2: Shizitan; 3: Donghulin; 4: Zhuannian; 5: Nanzhuangtou; 6: Shigu; 7: Peiligang, Shawoli, and Gangshi; 8: Egou; 9: Zhaigen and Bangou; 10: Niupiziwan; 11: Cishan; 12: Jiahu.

Table 1. Macro-botanical remains found in Upper Paleolithic and Early Neolithic sites in the middle Yellow River region.

\begin{tabular}{|c|c|c|c|c|}
\hline Site & Method & Cultigen & Wild plants & Reference \\
\hline Shizitan 9 & flotation & & Chenopodiaceae, Echinochloa sp. Setaria sp. Paniceae tribe & Bestel et al. 2014 \\
\hline Jiahu & flotation & rice & $\begin{array}{l}\text { wild rice, acorn (Quercus sp.), water caltrop, tubers, lotus } \\
\text { root, walnut, wild grape, soybean }\end{array}$ & $\begin{array}{l}\text { Zhao and Zhang } \\
2009\end{array}$ \\
\hline Peiligang & hand pick & $\begin{array}{l}\text { possible } \\
\text { foxtail millet }\end{array}$ & walnut, Plum, jujube & $\begin{array}{l}\text { Kaifeng 1978, } \\
\text { 1979; Zheng } 1984\end{array}$ \\
\hline Shawoli & hand pick & $\begin{array}{l}\text { possible } \\
\text { millet }\end{array}$ & walnut, jujube & $\begin{array}{l}\text { Institute of Ar- } \\
\text { chaeology } 1983\end{array}$ \\
\hline Egou & hand pick & & acorn (Q. acutissima), walnut, jujube & $\begin{array}{l}\text { Henan Provincial } \\
\text { Museum } 1981\end{array}$ \\
\hline Shigu & hand pick & & hazelnut, walnut, jujube, elm fruit & $\begin{array}{l}\text { Henan Institute } \\
1987\end{array}$ \\
\hline Shuiquan & hand pick & & $\begin{array}{l}\text { acorn (cf. Q. variabilis), walnut (Juglans mandshurica), jujube } \\
\text { (Zizyphus jujube) }\end{array}$ & $\begin{array}{l}\text { Henan 1st Team } \\
1995\end{array}$ \\
\hline Tieshenggou & hand pick & & fruits and nuts & $\begin{array}{l}\text { Fu 1980; Kaifeng } \\
\text { 1980; Institute of } \\
\text { Archaeology } 1986\end{array}$ \\
\hline Wuluo Xipo & flotation & foxtail millet & nuts, foxtail grass, Panic grass & Lee et al. 2007 \\
\hline Fudian & flotation & foxtail millet & foxtail grass & $\begin{array}{l}\text { Lee et al. } 2007 \\
\text { Bestel et al. } 2014\end{array}$ \\
\hline
\end{tabular}

\section{PLANT EXPLOITATION DURING THE TRANSITIONAL PERIOD (23,000-9000 CAL. BP)}

The best information for the reconstruction of plant foraging during the Upper Paleolithic period comes from the Shizitan site cluster in Shanxi. This is a series of more than 50 Upper Paleolithic localities (ca. 25,000-8500 cal. $\mathrm{BP})$ distributed within $15 \mathrm{~km}$ along the Qingshui River, a tributary of the Yellow River. All these localities are characterized primarily by a microlithic technology, with no pottery, dwelling structures, human burials, or storage facilities found, suggesting that the occupants were mobile hunter-gatherers (Linfen Cultural Bureau 1989; Shi 2011; Shizitan Archaeology Team 2002; 2013). 
During the last glacial maximum period (LGM; 26,500-19,000 cal BP), the climate in the Shizitan region was dry and cold, featuring a steppe environment. Between ca. 18,500 and 13,200 cal. BP this region experienced the last deglaciation, characterized by a mild and arid or semi-arid steppe environment with a small amount of deciduous and broadleaved species. This episode was then followed by a dry and cold period dating to 13,200 $13,000 \mathrm{cal}$. BP before another era of improved climatic conditions from 13,000 to $8400 \mathrm{cal}$. BP (Song 2011: 167). The last episode was punctuated by a short period of colddry conditions, known as the Younger Dryas (YD; 12,900-11,700 cal. BP), before the onset of the Holocene with its warm and wet climate.

Grinding stones were uncovered from several localities, and seven from Locality 14 and Locality 9 have been analyzed (Figure 2).

Shizitan 14 (ca. 23,000-18,000 cal. BP) was occupied primarily during the LGM. Three sandstone slabs, dating to ca. 23,000-19,500 cal. BP, were subjected to residue and usewear analyses. The total of 136 starch grains recovered were dominated by Triticeae tribe grasses (33\%), followed by Dioscorea sp. yam (18\%), beans of the Fabaceae family (15\%), Paniceae grasses $(13 \%)$, and Trichosanthes kirilowii snakegourd root (11\%) (Liu et al. 2013a) (Figure 3).

Shizitan 9 (ca. 13,800-8,500 cal. BP) was occupied during a period of transition from the Pleistocene to the Holocene, when the climate changed from cold-dry (YD) to warm-wet conditions (Holocene). Carbonized seeds of wild millets (Setaria and Echinochloa spp.) and goosefoot (Chenopodium sp.) are present in flotation samples, dating to $13,800-11,600$ cal BP (Bestel et al. 2014). Four grinding stones (two slabs and two handstones), dating to 12,700-11,600 cal BP, were analyzed for plant residues. A total of 212 starch grains were recovered, with most being derived from a tool unearthed from a later occupation stratum dating to the onset of Holocene. The great majority of starch grains are from grasses, including Panicoideae (most likely Paniceae) (38\%) and Triticeae tribe grasses (26\%); Quercus sp. acorns (26\%) appeared for the first time; and small proportions of starch belong to tubers (snakegourd root, 2\%; and yam, 2\%) and beans (2\%) (Liu et al. 2011) (Figure 3).

\section{Summary}

Paniceae grass starch on the Shizitan 14 grinding stones constitutes, to date, the earliest and most direct evidence for human consumption of these types of grasses in North China. The Paniceae tribe includes Setaria italica ssp. viridis (green foxtail grass), which is the wild ancestor of Setaria italica ssp. italica (domesticated foxtail millet). Carbonized foxtail millet seeds showing an early stage of domesticated morphology have been identified at the Donhulin site in Beijing (ca. 10,000 cal BP) (Zhao 2014). Some of the Paniceae starch grains on the Shizitan 14 grinding stones resemble modern reference samples from $S$. $i$. ssp. viridis, indicating that wild millet was exploited more than 10,000 years before its cultivation/domestication.
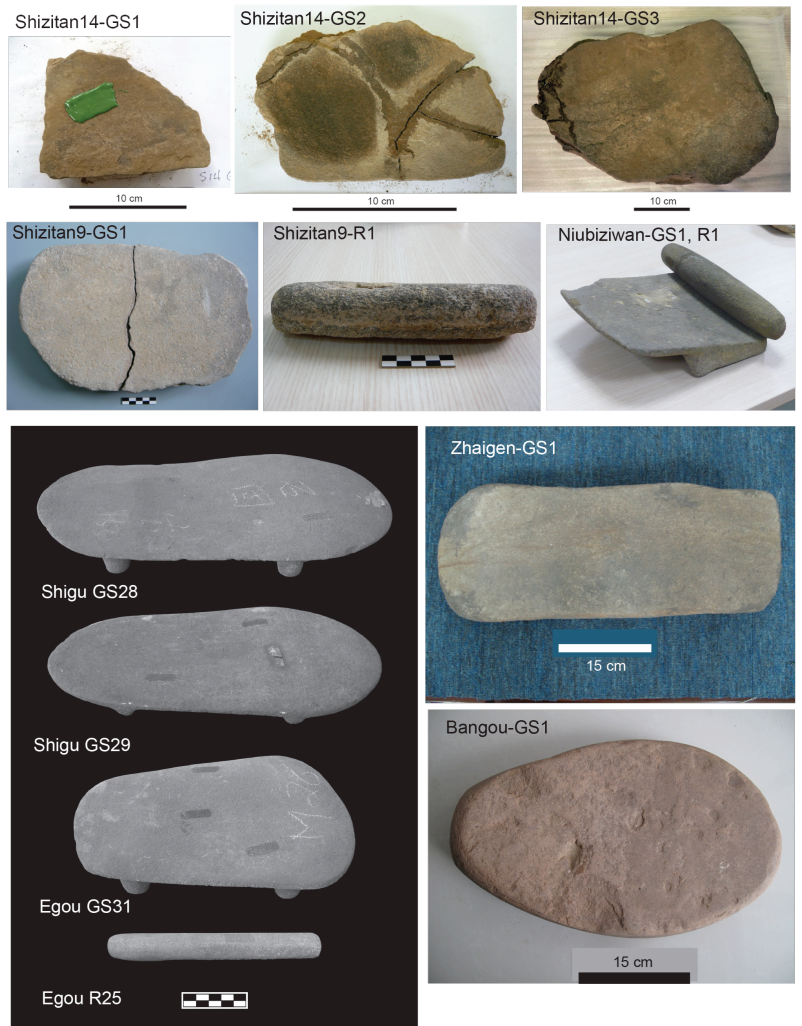

Figure 2. Representative grinding stones analyzed for residue remains and usewear traces discussed in this study.

Some of the Paniceae starch grains from Shizitan 9 are likely to have also derived from Setaria sp., as carbonized seeds of this genus with wild morphology have been found on the lower strata of the site (Bestel et al. 2014). Plant residues on pottery from Zhuannian in Beijing (ca. 10,000 cal BP) (Yang et al. 2014), as well as on grinding stones from Donghulin in Beijing and Nanzhuangtou in Hebei (ca. 11,500-11,000 cal BP) (Yang et al. 2012a) also contain significant proportions of Paniceae starch grains. These data indicate that intensive exploitation of smallgrained cereals was widespread in North China. If the Donghulin millet seeds already show morphological change due to human selection, as mentioned above, then pre-domestication cultivation of millet may have originated in hunting-gathering groups of the terminal Pleistocene, such as Shizitan 9. This hypothesis needs to be tested with more data in the future.

Triticeae grass starch grains account for significant proportions of the starch assemblages from both Shizitan 14 and Shizitan 9. Many taxa in the Triticeae tribe are indigenous to north China and still found in Shanxi today (Liu and Yue 2004). These include genera of Agropyron, Elymus, Roegneria, and Leymus. Triticeae starch grains have also been found on flaked stone tools from Shuidonggou in Ningxia (ca. 30,000-20,000 cal. BP) (Guan et al. 2014), as well as on grinding stones and pottery vessels at the early Holocene sites of Donghulin, Zhuannian 
and Nanzhuangtou (Yang and Perry 2013; Yang et al. 2014). Despite a long history of exploitation of Triticeae grasses in North China, these plants have never gone through a domestication process in any part of the world.

Beans (in the Fabaceae family) appear to have been one of the earliest plant foods used by hunter-gathers in North China. The earliest known macrobotanic remains of starch-rich beans have been identified as Adzuki bean (Vigna angularis), dating to the late Neolithic in Shandong (Crawford et al. 2005). It is possible that some genera of beans were indigenous in north China, and used long before the Neolithic period.

Dioscorea sp. Yam and Trichosanthes snakegourd root are tubers which rarely survive in an identifiable form in the archaeological record under normal conditions in China. Their starch grains, however, are clearly different from those of grasses, beans, and nuts, and have been identified in many sites. Starch analysis, therefore, is to date the best method to recover such plants. These tubers are distributed widely in North China today, and used as traditional medicine ( $\mathrm{Lu}$ and Chen 1986:218, 244-245; Pei and Ding 1985:103-105). Whereas yams have been commonly cultivated and cooked as food, snakegourd root has not been regularly consumed in North China except when used as a famine food. Snakegourd roots were skinned, cut into slices, and soaked in water for four to five days with the water changed each day. The roots were then ground with tools and sieved with textile to produce very fine flour. Alternatively, the roots might be dried and ground before being leached more than 20 times to make very fine flour. The flour then could be used to make cakes or noodles (Zhu 1406). It is important to note that the snakegourd root needs to be ground to flour for consumption, a scenario in line with the starch found on grinding stones in ancient sites.

Quercus acorn: The starch assemblages from the two Shizitan localities are alike, all including similar taxa of tubers, grasses, and beans. The exception is Quercus acorn, which was absent at Shizitan 14, but present at Shizitan 9. This change is consistent with the pollen profiles from the region where Quercus sp. appeared in the onset of the Holocene as the climate became warmer and wetter (Xia et al. 2002). This new type of food resource seems to have been soon exploited by humans at Shizitan. Acorn contains a considerable concentration of tannins, which need to be removed by grinding and leaching before human consumption (Mason 1996). The pre-existing technology for processing snakegourd roots, which included grinding and leaching, may have helped Shizitan people to utilize this new but toxic nut.

\section{PLANT EXPLOITATION DURING THE EARLY NEOLITHIC PERIOD (CA. 8500-7000 CAL BP)}

Currently there is a lack of data in the archaeological record about plant use during the early Holocene in the Middle Yellow River region, but we have better knowledge about the early Neolithic remains. They are represented by the Peiligang and Cishan cultures, coinciding with an episode of warm and wet climatic conditions known as the mid-Holocene climatic optimum. Most sites in this region are small settlements. Excavations have revealed remains of houses, burials, ash pits, pottery, and stone tools, indicating a high level of sedentary lifestyle. Millet domestication was already underway, indicated by the presence of carbonized millet grains and phytolith remains with clear characteristics of a domesticated morphology (Lee et al. 2007; Lu et al. 2009). Grinding stones (slabs and elongated handstones) account for significant proportions of lithic tool assemblages. Compared with the Paleolithic artifacts, the early Neolithic grinding stones are more regular in shape and larger in size, suggesting a more intensive use of these food processing implements (Figure 2). This typological change may be related to an increased population density and a higher degree of sedentism.

\section{Grinding stones from the Peiligang culture}

Grinding stones from seven Peiligang culture sites have been subjected to residue analysis. These include five sites located on the floodplains of central Henan (Egou, Shigu, Peiligang, Shawoli, and Gangshi) (Liu et al. 2010a; Zhang 2011; Zhang et al. 2011b) and two sites situated on the southern bank of the Yellow River in Mengjin county, western Henan (Zhaigen and Bangou) (Liu et al. 2013b). A total of 25 grinding stones from these sites were analyzed and more than 2800 starch granules recovered, identifiable to eight taxa. The predominant starch grains belong to acorn, Triticeae grasses, snakegourd root, Job's tears (Coix lacryma-jobi), and millet, while only a few grains are identifiable as beans, Dioscorea sp. yam, and other tubers (Table 2; Figure 3).

Most plants found in Peiligang starch assemblages are similar to those in the late Paleolithic Shizitan sites, with the exception of Job's tears, which belongs to Andropogoneae tribe of Panicoideae subfamily. Job's tears and millets show considerable overlapping in starch morphology, but several features of Job's tears starch differ from those seen in millets. A statistical model has been recently developed to separate Job's tears from millets, and successfully applied to ancient assemblages, including the case of Zhaigen discussed in this paper (Liu et al. 2014). However, several previously published reports of starch remains do not benefit from this new method. Therefore, some Panicoideae-type starch assemblages exhibiting characteristics of Job's tears and millets, taken from Peiligang culture sites, can only be identified as Job's tears/millet (Table 2).

\section{Grinding stones in the Cishan culture}

Grinding stones from two Cishan culture sites (Niupiziwan in Wuxiang, Shanxi province, and Cishan in Wu'an, Hebei province) have been studied to recover starch remains.

Niupiziwan is located in the western part of the Taihang Mountains. A set of grinding stones (a broken slab and a handstone) discovered there was analyzed. A total of 92 starch grains were found, including Quercus acorn $(32 ; 35 \%)$, Triticeae grasses $(25 ; 27 \%)$, Paniceae grasses, 
possibly including domesticated millet $(16 ; 17 \%)$, snakegourd root $(4 ; 4 \%)$, and beans $(2 ; 2 \%)$ (Liu et al. 2014). The mountainous ecosystem around Niupiziwan was likely similar to that of Shizitan, and the starch assemblages from Niupiziwan and Shizitan S9 are almost identical in terms of the plant taxa recovered on grinding stones. These include high proportions of small-grained seeds (wild and domesticated) from the Triticeae and Paniceae tribes. Millet starch grains have also been recovered from grinding stones at the Cishan site (Yang et al. 2012b), although the details of the entire starch assemblage have not been published.
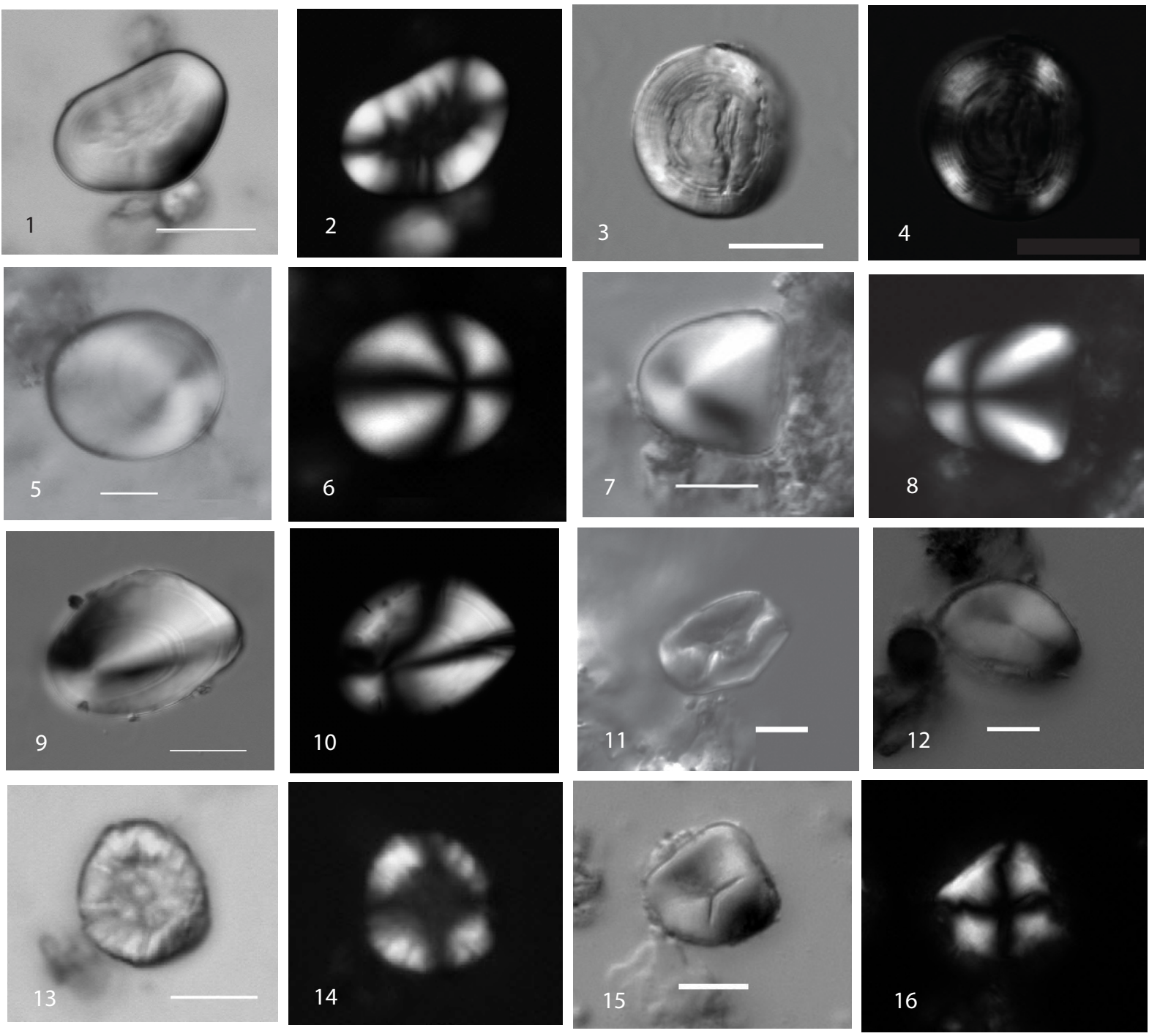

Figure 3. Representative starch grains uncovered from grinding stones (each starch grain is shown in DIC and polarized views). 1,2: Bean; 3,4: Triticeae grass; 5-8: Trichosanthes kirillowii snakegourd root; 9,10: Dioscorea sp. yam; 11,12: Quercus acorn; 13,14:

Paniceae millet grass; 15,16: Coix lacryma-jobi Job's tears (1-10, 13,14: Shizitan 14; 11: Shizitan 9; 12, 15,16: Zhaigen; scale: 1.3.9: $20 \mu \mathrm{m} ; 5,7,11-16: 10 \mu \mathrm{m})$.

\section{DISCUSSION}

The results of starch analysis on grinding artifacts shed light on a long history of intensive plant exploitation in the Middle Yellow River region. The plant residues on Shizitan 14 grinding stones provide the earliest direct evidence for human use of a wide range of plant foods during the LGM. The presence of high percentages of Triticeae and Paniceae starch on grinding tools from Shizitan 14 (46\% of the total) and Shizitan $9(50 \%$ of the total) indicates intensive collecting of small-grained grasses, in addition to tubers and beans, in the Qingshui River valley. This observation is consistent with the grassdominated ecosystem of the region as suggested by pollen analysis (Xia et al. 2002).

The intensive exploitation of these grasses during the LGM at Shizitan may have been related to an adaptation to the harsh environment. Given that Upper Paleolithic sites are unusually dense along the Qingshui River, there may also have been a considerable level of population pressure in the area, as people in other less hospitable 
regions may have retreated to a few refuges, like the Qingshui River valley, where natural resources were relatively abundant. Currently we know little about plant exploitation before the LGM in the Shizitan area; further research is needed to extend our knowledge to a deeper history of plant-based subsistence strategies there.

Wild millets appear to have been targeted for intensive collection in the Upper Paleolithic, leading to processes of domestication for these very small-seeded cereals. Indigenous Triticeae grasses commonly found in north China include genera of Agropyron, Elymus, Roegneria, and Leymus, which all produce seeds larger than millet. Triticeae grasses were evidently collected for food, based on starch remains, but none of them has ever been domesticated. More studies are needed to understand why millets, rather than other grasses, were cultivated and domesticated.

Job's tears is an annual plant, growing in moist soil conditions and native to tropical and sub-tropical regions of Asia. It has a range of variation in fruit type, shape and size. There are two species of Job's tears with several variants in China: Coix lacryma-jobi Linnaeus (yiyi in Chinese) with four variations, and Coix aquatic (shuisheng yiyi in Chinese). The cultivated C. lacrymajobi var. lacryma-jobi exhibits a bony utricle and is grown for decorative purposes (e.g., as beads for making necklaces), while $C$. $l$. var. ma-yuen has a thinner utricle and is produced for food and medicine (Chen and Phillips 2006). It has been suggested that wild forms of Coix have harder and bonier utricles, and the cultivated thin-utricle races of Coix originated through gene mutation from the wild forms as a result of conscious selection by humans for easy husking (Arora 1977). Job's tears, wild and/or domesticated, is widely distributed in most parts of China except for Qinghai, Gansu, and Ningxia (Huang et al. 1995). This plant produces much larger seeds than millet, and its use for food appears to have had a very long history in China. Starch grains of Job's tears have been found on pottery at Kuahuqiao in the Lower Yangzi River region (Yang and Jiang 2010), in addition to grinding stones from several Peiligang culture sites discussed in the current study, all dating to the early Neolithic. The macroremains of Job's tears, however, have been found mostly in waterlogged or desiccated conditions. These are seeds found at Hemudu in Zhejiang (7000-5000 cal BP) (Zhejiang Institute of Archaeology 2003), Chengtoushan in Hunan (6400-6200 cal BP) (Liu and Gu 2007), Baodun in Sichuan (4700-4000 cal BP) (Guedes et al. 2013), and well-preserved involucres from Sampula in Xinjiang (2000 cal BP) (Jiang et al. 2008).

Job's tears was not only commonly consumed as food in ancient times, but also assumed symbolic meanings. As recorded in ancient texts, it was associated with the birth of the legendary king, Yu the Great (Zhao et al. 1995). This plant apparently enjoyed much greater economic and social significance than we have recognized previously. Nevertheless, the process of its domestication remains elusive. Given that its native habitation is in tropical and sub-tropical regions, it is unclear if the Peiligang culture area was outside the natural distribution area of wild Job's tears, and if this plant was brought to the Yellow River valley by humans through cultivation. These questions need to be addressed in future research.

Tubers (snakegourd root and yam) were collected and processed continuously from the Paleolithic to the Neolithic, regardless of the emergence of millet domestication. Tubers and acorns were particularly predominant in the Peiligang starch assemblages. Such extensive use of tubers in the prehistory of the Middle Yellow River region is new knowledge, owing to the employment of starch analysis. The tradition of collecting and processing snakegourd root and yam as staple foods for such a long period of time also raises a question about their domesticity, a topic that also needs to be explored in the future.

\section{CONCLUSION}

This paper uses the data generated from residue analysis on grinding stones, integrated with macro-botanic information, to investigate the plant exploitation practiced in various ecological settings in the Middle Yellow River valley. Starch assemblages from Paleolithic and Neolithic sites dating from 23,000 to 7000 cal BP provide a broad picture showing how the transition to agriculture and pathways to Neolithization may have taken place in this region.

The intensive exploitation of diverse plants (including tubers, grasses, and beans), processed with grinding stones, was practiced during the LGM among Paleolithic populations who occupied small river valleys with relatively abundant natural resources. More studies are needed to understand the plant use prior to the LGM in this region in order to understand a deeper tradition of plant use and to evaluate the impact of climatic change on human subsistence adaptation there.

Pre-domestication cultivation may have occurred during the Younger Dryas (YD), prior to the Holocene. This hypothesis is based on the observation that morphologically recognizable domesticated millet was first present at Donghulin dating to the beginning of the Holocene, and pre-domestication cultivation may predate morphological domestication by a millennium or more (Willcox 2012). The cold and dry climate coupled with population pressure in a few favorable areas during the YD may have triggered the start of cultivating small-grained grasses in the Levant of the Near East (Bar-Yosef 2011). Further research should investigate if a similar process also occurred in north China.

The development towards full agriculture with morphological domestication of millets in the early Neolithic Middle Yellow River valley is characterized by a continuation of the broad-spectrum subsistence strategy. Millet domestication occurred in conjunction with collecting many taxa of other plants, particularly tubers, Job's tears, acorn, and wild grasses. A regional difference is also observable between the composition of starch assemblages from the mountainous regions in Shanxi and the floodplains in Henan. Grass and acorn starch grains account for significant proportions in Shizitan 9 and Niupiziwan as- 
semblages from Shanxi. In contrast, starch grains from the sites in Henan are predominantly tubers, acorns, and Job's tears. Since the research area is rather small, further study on plant use over a broader region is needed to see if this pattern holds.

Macro- and micro-botanical analyses are clearly complementary to one another. While macro-botanical analysis of plants' morphological changes provides crucial information for determining their domesticity, microbotanical research can recover starchy plants that may not survive well in normal archaeological conditions, or are not easily identifiable in macro-botanical remains. In the examples discussed in this paper, millet remains have been found in both flotation and residue samples; soybean, which contains little starch, was recovered in flotation samples; but Job's tears, yam, snakegourd root, Triticeae grasses, and some beans have all been recovered only from starch residues. Archaeobotany is in an early stage of development in China; therefore, it is important to combine both approaches for a more complete documentation of plant use in the past and a better understanding of subsistence practices.

\section{ACKNOWLEDGEMENTS}

I thank two anonymous reviewers for their very constructive comments. 
Table 2. Starch grains uncovered from grinding stones discussed in the text.

\begin{tabular}{|c|c|c|c|c|c|c|c|c|c|c|c|c|c|c|c|c|}
\hline Site & Culture & $\begin{array}{l}\text { Date } \\
\text { cal. BP }\end{array}$ & $\begin{array}{l}\text { No. } \\
\text { of } \\
\text { tools }\end{array}$ & $\begin{array}{l}\text { No. of } \\
\text { starch }\end{array}$ & $\begin{array}{l}\text { Snakegourd } \\
\text { root }\end{array}$ & Yam & Acorn & $\begin{array}{l}\text { Tritice- } \\
\text { ae } \\
\text { grass }\end{array}$ & $\begin{array}{l}\text { Wild } \\
\text { millet }\end{array}$ & $\begin{array}{l}\text { Wild/ } \\
\text { dom. } \\
\text { millet }\end{array}$ & $\begin{array}{l}\text { Job's } \\
\text { tears }\end{array}$ & $\begin{array}{l}\text { Job's } \\
\text { tears/ } \\
\text { millet } \\
\end{array}$ & Beans & Tubers & $\begin{array}{l}\text { Uniden- } \\
\text { tified }\end{array}$ & Reference \\
\hline \multicolumn{17}{|l|}{ Shanxi province } \\
\hline Shizitan 14 & $\begin{array}{l}\text { Upper } \\
\text { Paleo. }\end{array}$ & $\begin{array}{l}23,000- \\
19,500\end{array}$ & 3 & 136 & 15 (11\%) & $\begin{array}{l}24 \\
(18 \%)\end{array}$ & & $\begin{array}{l}45 \\
(33 \%)\end{array}$ & $\begin{array}{l}18 \\
(13 \%)\end{array}$ & & & & $\begin{array}{l}20 \\
(15 \%)\end{array}$ & & $\begin{array}{l}14 \\
(13 \%)\end{array}$ & $\begin{array}{l}\text { Liu et al. } \\
2013 a\end{array}$ \\
\hline Shizitan 9 & $\begin{array}{l}\text { Upper } \\
\text { Paleo. }\end{array}$ & $\begin{array}{l}12,700- \\
11,600\end{array}$ & 4 & 212 & $4(2 \%)$ & $\begin{array}{l}5 \\
(2 \%)\end{array}$ & $\begin{array}{l}56 \\
(26 \%)\end{array}$ & $\begin{array}{l}26 \\
(12 \%)\end{array}$ & $\begin{array}{l}80 \\
(26 \%)\end{array}$ & & & & $4(2 \%)$ & & $\begin{array}{l}37 \\
(17 \%)\end{array}$ & $\begin{array}{l}\text { Liu et al. } \\
2011\end{array}$ \\
\hline $\begin{array}{l}\text { Niupiziwan } \\
\text { Henan province }\end{array}$ & Cishan & 7000 & 2 & 92 & $4(4 \%)$ & & $\begin{array}{l}32 \\
(35 \%)\end{array}$ & $\begin{array}{l}25 \\
(27 \%)\end{array}$ & & $\begin{array}{l}16 \\
(17 \%)\end{array}$ & & & $2(2 \%)$ & & $\begin{array}{l}13 \\
(14 \%)\end{array}$ & $\begin{array}{l}\text { Liu et al. } \\
2014\end{array}$ \\
\hline Zhaigen & $\begin{array}{l}\text { late } \\
\text { Peiligang }\end{array}$ & 7000 & 1 & $>1050$ & са. 1000 & & 1 & 16 & & & 26 & & & & 9 & $\begin{array}{l}\text { Liu et al. } \\
2013 b\end{array}$ \\
\hline & & & & & & & 4 & & & & & & & & & $\begin{array}{l}\text { Liu et al. } \\
\text { 2013b }\end{array}$ \\
\hline Bangou & Peiligang & $\begin{array}{l}7000 \\
8500-\end{array}$ & 1 & 29 & $15(52 \%)$ & & $(14 \%)$ & $4(14 \%)$ & & & & & & & $6(21 \%)$ & $\begin{array}{l}\text { Liu et al. } \\
2010\end{array}$ \\
\hline Egou & Peiligang & $\begin{array}{l}7000 \\
8500-\end{array}$ & 3 & 318 & prest & prest & prest & & prest & & & & prest & & prest & $\begin{array}{l}\text { Liu et al. } \\
2010\end{array}$ \\
\hline Shigu & Peiligang & 7000 & 3 & 22 & 1 & & & & & & & & & & 21 & \\
\hline $\begin{array}{l}\text { Egou, Shigu, } \\
\text { Shawoli, } \\
\text { Gangshi }\end{array}$ & Peiligang & $\begin{array}{l}8500- \\
7000\end{array}$ & 7 & 396 & & & $\begin{array}{l}132 \\
(33 \%)\end{array}$ & $\begin{array}{l}90 \\
(23 \%)\end{array}$ & & & & $\begin{array}{l}93 \\
(23 \%)\end{array}$ & & & $\begin{array}{l}81 \\
(20 \%)\end{array}$ & $\begin{array}{l}\text { Zhang et } \\
\text { al. } 2011\end{array}$ \\
\hline Peiligang & Peiligang & $\begin{array}{l}8500- \\
7000 \\
\end{array}$ & 8 & 1069 & & & $\begin{array}{l}495 \\
(46 \%)\end{array}$ & $\begin{array}{l}260 \\
(24 \%)\end{array}$ & & & & $\begin{array}{l}129 \\
(12 \%) \\
\end{array}$ & & $\begin{array}{l}4 \\
(0.4 \%) \\
\end{array}$ & $\begin{array}{l}181 \\
(17 \%)\end{array}$ & $\begin{array}{l}\text { Zhang } \\
2011\end{array}$ \\
\hline
\end{tabular}




\section{REFERENCES}

Adams, J. L. 2010. Understanding grinding technology through experimentation. Designing Experimental Research in Archaeology. J. R. Ferguson. Boulder: University Press of Colorado: 129-152.

Archaeology Department at Peking University, Archaeology Center at Peking University, and Beijing Institute of Archaeology. 2006. Beijingshi Mentougouqu Donghulin shiqian yizhi (The Donghulin prehistoric site in Mentougou, Beijing). Kaogu 7: 3-8. (in Chinese)

Arora, R. K. 1977. Job's-Tears (Coix lacryma-jobi): A Minor Food and Fodder Crop of Northeastern India. Economic Botany 31(3): 358-366.

Bar-Yosef, O. 2011. Climatic fluctuations and early farming in West and East Asia. Current Anthropology 52(S4): S175S193.

Bestel, S., G. W. Crawford, L. Liu, J. Shi, Y. Song and X. Chen. 2014. The evolution of millet domestication, Middle Yellow River Region, North China: Evidence from charred seeds at the late Upper Paleolithic Shizitan Locality 9 site. The Holocene 24(3): 261-265.

Chen, S. and S. M. Phillips. 2006. Coix Linnaeus. Flora of China. 22: 648-649.

Crawford, G. W., A. Underhill, Z. Zhao, G.-A. Lee, F. Gary, L. Nicholas, F. Luan, H. Yu, H. Fang and F. Cai. 2005. Late Neolithic plant remains from northern China: preliminary results from Liangchengzhen, Shandong. Current Anthropology 46(2): 309-317.

Crawford, G. W., X. Chen, F. Luan and J. Wang. 2013. Shandong Jinan Changqing Yuezhuang yizhi zhiwu yicun de chubu fenxi (A Preliminary Analysis on Plant Remains of the Yuezhuang Site in Changqing District, Jinan City, Shandong Province). Jianghan Kaogu 2: 107-116.

Dubreuil, L. 2004. Long-term trends in Natufian subsistence: a use-wear analysis of ground stone tools. Journal of Archaeological Sceince 31(11): 1613-1629.

Ebeling, J. R. and Y. M. Rowan. 2004. The archaeology of the daily grind: Ground stone tools and food production in the Southern Levant. Near Eastern Archaeology 67(2): 108117.

Fu, Y. 1980. Gongxian Tieshenggou faxian Peiligang wenhua yizhi (The discovery of a Peiligang culture site at Tieshenggou in Gongxian). Henan Wenbo Tongxun 2: 2829. (in Chinese)

Fullagar, R. and J. Field. 1997. Pleistocene seed grinding implements from the Pleistocene Australian arid zone. Antiquity 71(272): 300-307.

Fullagar, R. and R. Jones. 2004. Usewear and residue analysis of stone artefacts from the enclosed chamber, Rocky Cape, Tasmania. Archaeol. Oceania 39: 79-93.

Fullagar, R. 2006. Starch grains, stone tools and modern hominin behaviour. An Archaeological Life: Papers in Honour of Jay Hall (Aboriginal and Torres Strait Islander Studies Unit Research Report Series 7). S. Ulm et al. Brisbane, Qld.: Aboriginal and Torres Strait Islander Studies Unit, The University of Queensland: 191-202.

Fullagar, R., J. Field and L. Kealhofer. 2008. Grinding stones and seeds of change: starch and phytoliths as evidence of plant food processing. New Approaches to Old Stones: Recent Studies of Ground Stone Artifacts. Y. M. Rowan and J. R. Ebeling. London: Equinox Press: 159-172.
Guan, Y., D. M. Pearsall, X. Gao, F. Chen, S. Pei and Z. Zhou. 2014. Plant use activities during the Upper Paleolithic in East Eurasia: Evidence from the Shuidonggou Site, Northwest China. Quaternary International http://dx.doi.org/10.1016/j.quaint.2014.04.007.

Guedes, J. d. A., M. Jiang, K. He, X. Wu and Z. Jiang. 2013. Site of Baodun yields earliest evidence for the spread of rice and foxtail millet agriculture to south-west China. Antiquity 87(337): 758-771.

Henan Institute of Cultural Relics. 1987. Changge Shigu yizhi fajue baogao (Excavation report of the Shigu site in Changge). Huaxia Kaogu 1: 3-125. (in Chinese)

Henan Provincial Museum. 1981. Henan Mixian Egou Beigang xinshiqi shidai yizhi (The Neolithic site at Egou Beigang in Mixian, Henan). Kaoguxue Jikan 1: 1-26, 48. (in Chinese)

Henan 1st Team, Institute of Archaeology, CASS. 1995. Henan Jiaxian Shuiquan Peiligang wenhua yizhi (The Peiligang culture site at Shuiquan in Jiaxian, Henan). Kaogu Xuebao 1: 39-78. (in Chinese)

Huang, H., P. Lu, Y. Zhu and Y. Li. 1995. Zhongguo yiyi de shengtaixing, duoyangxing ji liyong jiazhi (Ecotype, variety and value in use of Coix lachryma-jobi in China). Zuowu Pinzhong Ziyuan 4: 4-8. (in Chinese)

Institute of Archaeology, Chinese Academy of Social Sciences. 1983. Henan Xinzheng Shawoli xinshiqi shidai yizhi (The Neolithic site at Shawoli in Xinzheng, Henan). Kaogu 12: 1057-1065. (in Chinese)

Institute of Archaeology, Chinese Academy of Social Sciences. 1986. 1984 nian Henan Gongxian kaogu diaocha yu shijue (Archaeological survey and test excavation in Gongxian, Henan, 1984). Kaogu 3: 193-196. (in Chinese)

Jiang, H.-E., B. Wang, X. Li, E.-G. Lu and C.-S. Li. 2008. A consideration of the involucre remains of Coix lacrymajobi L. (Poaceae) in the Sampula Cemetery (2000 years BP), Xinjiang, China. Journal of Archaeological Science 35: 1311-1316.

Kaifeng Bureau of Cultural Relics Management. 1978. Henan Xinzheng Peiligang xinshiqi shidai yizhi (The Neolithic site of Peiligang in Xinzheng, Henan). Kaogu 2: 73-79. (in Chinese)

Kaifeng Bureau of Cultural Relics Management. 1979. Peiligang yizhi yijiuqiba nian fajue jianbao (Brief report of excavation at the Peiligang site in 1978). Kaogu 3: 197205. (in Chinese)

Kaifeng Bureau of Cultural Relics Management. 1980. Henan Gongxian Tieshenggou xinshiqi zaoqi yizhi shijue jianbao (Brief report of the test excavation of early Neolithic site at Tieshenggou in Gongxian, Henan). Wenwu 5: 16-19. (in Chinese)

Lee, G.-A., G. W. Crawford, L. Liu and X. Chen. 2007. Plants and people from the early Neolithic to Shang periods in North China. PNAS 104(3): 1087-1092.

Li, J., Q. Qiao and X. Ren. 2010. 1997 nian Hebei Xushui Nanzhuangtou yizhi fajue baogao (Report of excavation at the Nanzhuangtou site in Xushui, Hebei, in 1997). Kaogu Xuebao 3: 361-385. (in Chinese)

Linfen Cultural Bureau of Shanxi Province. 1989. Shanxi Jixian Shizitan Zhongshiqi wenhua yizhi (The Shizitan mesolithic culture site in Jixian, Shanxi). Kaogu Xuebao 3: 305-323. (in Chinese) 
Liu, C. 2006. Dadiwan yizhi zhiwu yicun jianding baogao (Identification of plant remains from the Dadiwan site). Qin'an Dadiwan. Gansu Institute of Cultural Relics and Archaeology. Beijing: Wenwu Press: 914-916. (in Chinese)

Liu, C. and H. Gu. 2007. Chengtoushan yizhi de zhiwu yicun. Chengtoushan in Lixian. Hunan Institute of Archaeology and Cultural Relics and International Research Center of Japanese Culture. Beijing: Wenwu Press: 98-106. (in Chinese).

Liu, L., G.-A. Lee, L. Jiang and J. Zhang. 2007. Evidence for the early beginning (c. 9000 cal. BP) of rice domestication in China: a response. The Holocene 17(8): 1059-1068.

Liu, L., J. Field, R. Fullagar, S. Bestel, X. Ma and X. Chen. 2010a. What did grinding stones grind? New light on Early Neolithic subsistence economy in the Middle Yellow River Valley, China. Antiquity 84(325): 816-833.

Liu, L., J. Field, R. Fullagar, C. Zhao, X. Chen and J. Yu. 2010b. A functional analysis of grinding stones from Donghulin, north China. Journal of Archaeological Science 37(10): 2630-2639.

Liu, L., W. Ge, S. Bestel, D. Jones, J. Shi, Y. Song and X. Chen. 2011. Plant exploitation of the last foragers at Shizitan in the Middle Yellow River Valley China: evidence from grinding stones. Journal of Archaeological Science 38(12): 3524-3532.

Liu, L., S. Bestel, J. Shi, Y. Song and X. Chen. 2013a. Paleolithic human exploitation of plant foods during the last glacial maximum in North China. Proceedings of the National Academy of Sciences 110(14): 5380-5385.

Liu, L., X. Chen and H. Zhao. 2013b. Henan Mengjin Zhaigen, Bangou chutu Peiligang wanqi shimopan gongneng fenxi (Functional analysis of grinding slabs of the late Peiligang culture from Zhaigen and Bangou in Mengjin, Henan). Zhongyuan Wenwu 5: 76-86. (in Chinese).

Liu, L., X. Chen and J. Shi. 2014. Shanxi Wuxiang Niupiziwan shimopan, mobang de weihen yu canliuwu fenxi (Usewear and residue analyses of the grinding stones from Niupiziwan in Wuxiang county, Shanxi province). Kaogu yu Wenwu 3: 109-119. (in Chinese).

Liu, L., S. Ma and J. Cui. 2014. Identification of starch granules using a two-step identification method. Journal of Archaeological Science 52: 421-427.

Liu, T. and J. Yue, Eds. 2004. Shanxi Zhiwuzhi (Flora of Shanxi). Beijing: Chinese Science and Technology Press. (in Chinese)

Lu, A. and S. Chen, Eds. 1986. Zhongguo Zhiwuzhi (Flora of China). Beijing: Science Press. (in Chinese)

Lu, H., J. Zhang, K.-b. Liu, N. Wu, Y. Li, K. Zhou, M. Ye, T. Zhang, H. Zhang, X. Yang, L. Shen, D. Xu and Q. Li. 2009. Earliest domestication of common millet (Panicum miliaceum) in East Asia extended to 10,000 years ago. Proceedings of the National Academy of Sciences of the United States of America 106: 6425-6426.

Lu, T. L.-D. 1999. The Transition from Foraging to Farming and the Origin of Agriculture in China. British Archaeological Report International Series 774. Oxford: BAR.

Mason, S. L. R. 1996. Acornutopia? Determining the role of acorns in past human subsistence. Food in Antiquity. J. Wilkins, D. Harvey and M. Dobson. Exeter: University of Exeter Press: 12-24.
Pei, J. and Z. Ding, Eds. 1985. Zhongguo Zhiwuzhi (Flora of China) Vol. 16.1. Beijing: Science Press. (in Chinese)

Piperno, D. R., E. Weiss, I. Holst and D. Nadel. 2004. Processing of wild cereal grains in the Upper Palaeolithic revealed by starch grain analysis. Nature 430(5 August): 670-673.

Revedin, A., B. Aranguren, R. Becattini, L. Longo, E. Marconi, M. M. Lippi, N. Skakun, A. Sinitsyn, E. Spiridonova and J. Svoboda. 2010. Thirty thousand-year-old evidence of plant food processing. Proceedings of the National Academy of Sciences 107(44): 18815-18819.

Shi, J. 2011. Shanxi zhongyao kaogu faxian -- Jixian Shizitan jiushiqi shidai yizhi (Important archaeological discoveries in Shanxi -- Paleolithic sites at Shizitan in Jixian). Zhongguo Wenwubao. Beijing: 6-7. (in Chinese)

Shizitan Archaeology Team. 2002. Shanxi Jixian Shizitan jiushiqi shidai yizhi S14 didian (Paleolithic Locality S14 at Shizitan in Jixian, Shanxi). Kaogu 4: 15-28. (in Chinese)

Shizitan Archaeology Team. 2010. Shanxi Jixian Shizitan yizhi dijiu didian fajue jianbao (Preliminary report of excavation at Locality 9 at the Shizitan site in Jixian, Shanxi). Kaogu 10: 7-17. (in Chinese)

Shizitan Archaeology Team. 2013. Shanxi Jixian Shizitan jiushiqi shidai yizhi S14 didian 2002-2005 nian fajue jianbao (Preliminary report of the 2002-2005 excavations at Locality 14 of the Paleolithic Shizitan site in Jixian, Shanxi). Kaogu 2: 3-13. (in Chinese)

Song, Y. 2011. Study on the Quartzite Artifacts in Shizitan Site, Jixian, Shanxi. Institute of Vertebrate Paleontology and Paleoanthropology Beijing: Chinese Academy of Sciences. Unpublished PhD dissertation. (in Chinese)

Van Peer, P., R. Fullagar, S. Stokes, R. M. Bailey, J. Moeyersons, F. Steenhoudt, A. Geerts, T. Vanderbeken, M. D. Dapper and F. Geus. 2003. The Early to Middle Stone Age transition and the emergence of Modern Human behaviour at site 8-B-11, Sai Island, Sudan. Journal of Human Evolution 45: 187-193.

Wang, J., X. Wang and Z. Chen. 1978. Xiachuan wenhua -Shanxi Xiachuan yizhi diaocha baogao (The Xiachuan Culture - Survey report of the Xiachuan site in Shanxi). Kaogu Xuebao 3: 259-288. (in Chinese)

Willcox, G. 2012. Pre-domestic cultivation during the Late Pleistocene and Early Holocene in the Northern Levant. Biodiversity in Agriculture: Domestication, Evolution, and Sustainability. P. Gepts, T. R. Famula, R. L. Bettinger, S. B. Brush, A. B. Damania, P. E. McGuire and C. O. Qualset. Cambridge: Cambridge University Press.

Wright, K. I. 1994. Ground-stone tools and hunter-gatherer subsistence in Southwest Asia: Implications for the transition to farming. American Antiquity 59(2): 238-263.

Wu, X., C. Zhang, P. Goldberg, D. Cohen, Y. Pan, T. Arpin and O. Bar-Yosef. 2012. Early pottery at 20,000 years ago in Xianrendong Cave, China. Science 336(6089): 1696-1700.

Xia, Z., G. Chen, G. Zheng, F. Chen and J. Han. 2002. Climate background of the evolution from Paleolithic to Neolithic cultural transition during the last deglaciation in the middle reaches of the Yellow River. Chinese Science Bulletin 47(1): 71-75.

Yang, X. and L. Jiang. 2010. Starch grain analysis reveals ancient diet at Kuahuqiao site, Zhejiang Province. Chinese Science Bulletin 55(12): 1150-1156. 
Yang, X., Z. Wan, L. Perry, H. Lu, Q. Wang, C. Zhao, J. Li, F. Xie, J. Yu, T. Cui, T. Wang, M. Li and Q. Ge. 2012a. Early millet use in northern China. Proceedings of the National Academy of Sciences 109(10): 3726-3730.

Yang, X., J. Zhang, L. Perry, Z. Ma, Z. Wan, M. Li, X. Diao and H. Lu. 2012b. From the modern to the archaeological: starch grains from millets and their wild relatives in China. Journal of Archaeological Science 39(2): 247-254.

Yang, X. and L. Perry. 2013. Identification of ancient starch grains from the tribe Triticeae in the North China Plain. Journal of Archaeological Science 40: 3170-3177.

Yang, X., Z. Ma, T. Wang, L. Perry, Q. Li, X. Huan and J. Yu. 2014. Starch grain evidence reveals early pottery function cooking plant foods in North China. Chinese Science Bulletin DOI 10.1007/s11434-014-0500-6.

Zhang, J.-F., X.-Q. Wang, W.-L. Qiu, G. Shelach, G. Hu, X. Fu, M.-G. Zhuang and L.-P. Zhou. 2011a. The Paleolithic site of Longwangchan in the middle Yellow River, China: Chronology, paleoenviornment and implications. Journal of Archaeological Science 38(7): 1537-1550.

Zhang, Y. 2011. Peiligang wenhua zhiwulei shiwu jiagong gongju biaomian dianfenli yanjiu (Study of starch grains on the plant food processing tools from the Peiligang culture). Department of Archaeology and Museuology. Hefei: University of Science ad Technology of China. Unpublished MA thesis. (in Chinese)

Zhang, Y., Y. Weng, L. Yao, J. Zhang, Y. Zhou, F. Fang and W. Cui. 2011b. Peiligang Yizhi chutu shimopan biaomian dianfenli de jianding yu fenxi (Identification and analysis of starch grains on the grinding slabs from the Peiligang site). Quaternary Sciences 31(5): 891-899. (in Chinese).

Zhao, X., X. Song and G. Li. 1995. Yiyi mingshikao (on the meaning of Job's tears). Zhongguo Nongshi 14(2): 34-38. (in Chinese)

Zhao, Z. and J. Zhang. 2009. Jiahu yizhi 2001 niandu fuxuan jieguo fenxi baogao (Report of flutation results from the 2001 season at the Jiahu site). Kaogu 8: 84-93. (in Chinese)

Zhao, Z. 2011. New archaeobotanic data for the study of the origins of agriculture in China. Current Anthropology 52(S4): S295-S306.

Zhao, Z. 2014. Zhongguo gudai nongye de xingcheng guocheng -- Fuxuan chutu zhiwu yicun zhengju (The process of origin of agriculture in China: Archaeological evidence from flotation)results. Quaternary Sciences 34(1): 73-84. (in Chinese).

Zhejiang Institute of Archaeology. 2003. Hemudu. Beijing. (in Chinese): Wenwu Press. (in Chinese)

Zheng, N. 1984. 1979 nian Peiligang yizhi fajue baogao (Report of excavation at the Peiligang site in 1979). Kaogu Xuebao 1: 23-51.

Zhu, S., Ed. 1406. Jiuhuang Bencao (Herbal for Relief of Famines). Siku Quanshu Di 730 Ce (Complete Library of the Four Treasuries, vol.730). Taipei: Shangwu Press. (in Chinese) 